\title{
The Attitude, Perception, and Mental Health of Patients Receiving Orthodontic Treatment During the COVID-I9 Pandemic in Saudi Arabia
}

\author{
Ahmed Mohammed Alassiry', Zaki Hakami (iD) ${ }^{2}$ \\ 'Preventive Dental Sciences Department, Faculty of Dentistry, Najran University, Najran, Saudi Arabia; ${ }^{2}$ Division of Orthodontics, Department of \\ Preventive Dental Sciences, College of Dentistry, Jazan University, Jazan, Saudi Arabia \\ Correspondence: Zaki Hakami, Division of Orthodontics, Department of Preventive Dental Sciences, College of Dentistry, Jazan University, Jazan, \\ Saudi Arabia, Tel +966-5447020I I, Email zhakami@jazanu.edu.sa
}

\begin{abstract}
Purpose: The COVID-19 pandemic has forced dental clinics to shut down indefinitely, leaving thousands of orthodontic patients in unending fear and dismay. The study aimed to assess the attitude, perceptions and mental health status of patients undergoing orthodontic treatment in Saudi Arabia during the lockdown.

Patients and Methods: A cross-sectional study was conducted among orthodontic patients of different clinics across Saudi Arabia and selected using two-stage clustered sampling. A validated Arabic questionnaire comprising four sections including demographic data, patients' interactions, attitude and perception, and Kessler Psychological Distress Scale was sent via digital means. Descriptive and inferential statistics were applied with the level of significance set to $\mathrm{p}<0.05$.

Results: A total of 512 orthodontic patients voluntarily participated in the study. Eighty-four percent of the patients contacted their orthodontist once or twice during this period, $22 \%$ percent did not receive any communication from their orthodontist, $18 \%$ were very worried about not being able to continue their treatment, $72 \%$ were concerned about the treatment duration increasing post lockdown, $18 \%$ suffered cuts or lacerations due to their appliance, and $32 \%$ had poking wires. Seventy-six percent of patients were willing to visit a clinic post lockdown only with proper preventive measures in place. A mild level of mental distress (22.76 \pm 8.69$)$ was reported using the Kessler Psychological Distress Scale. Female orthodontic patients $>25$ years of age with $>1$ year of ongoing treatment were associated with higher levels of mental distress.

Conclusion: The current pandemic has impacted the mental health status of orthodontic patients in some form or another. Older females with longer treatment times were more affected by the lockdown. The lack of effective communication from the orthodontist led to some negative perceptions about their treatment.
\end{abstract}

Keywords: COVID-19, Saudi Arabia, orthodontics, mental health, attitude, perception

\section{Introduction}

The end of the last decade was unwelcomed by the outbreak of the novel coronavirus (SARS-CoV-2) from Wuhan, China. Within a short time, major populations around the world were grappling with the fear of this newly named coronavirus (COVID-19). This unprecedented global health crisis was declared as a global pandemic by the World Health Organization in March 2020. ${ }^{1}$ The rapid spread of the virus along with its high infectivity and unknown pathogenicity caused extreme panic, chaos, and confusion. Even modern governments and elite healthcare facilities began witnessing the biggest healthcare, administrative and financial crisis of the century.

In Saudi Arabia, the pandemic was first detected in a Saudi traveler from Iran, who tested positive for COVID-19 on March 2, 2020. ${ }^{2}$ Like other governments of the world, partial curfews and lockdowns were imposed by the Kingdom to limit the spread of pandemic. Only essential services were permitted to continue and only workers with permits were allowed to exit their homes. ${ }^{3}$ As a result of this mandate, dental clinics and institutions had to close across Saudi Arabia, leaving only emergency services operational. Dental procedures carry a high risk of contamination and cross infection. 
Aerosols, saliva, blood, and respiratory droplets are potential routes of viral transmission. ${ }^{4}$ Treating infected patients or coming in indirect contact with them through fallen droplets over surfaces can be a high-risk affair for a dental professional, their team, patients, and family members. ${ }^{5}$ Hence, it was suggested by dental health organizations that only true dental emergencies should be attended to with infection control measures, while routine and elective dental treatment should be delayed. ${ }^{6}$

Orthodontic treatment and esthetic procedures are not considered as medical emergencies. Hence, all orthodontic appointments were cancelled, and their treatment was delayed indefinitely. Orthodontic treatment is usually of long duration and requires multiple visits. Moreover, the treatment contributes to the esthetics, beauty, and mental body image of the patient. Therefore, the treatment is sensitive to the delays caused by closed clinics and missed appointments. The unspecified nature of the pandemic and unknown duration of lockdowns make the scenario worse for an orthodontic patient. This has led to varying levels of mental distress and anxiety for patients who are unable to visit a clinic and continue their respective treatment. ${ }^{7}$ The aim of this study was to evaluate the mental health status of patients undergoing orthodontic treatment during the COVID-19 pandemic in Saudi Arabia. Moreover, this study analyzed the anxiety levels and challenges faced by orthodontic patients and their perception towards treatment.

\section{Methods}

\section{Study Design}

Patients currently undergoing orthodontic treatment in various dental clinics across Saudi Arabia were included in this cross-sectional study. The method of two-stage cluster sampling was utilized. In the first stage, Saudi Arabia was divided into 5 subregions: north, south, east, west, and center. In the second stage, a dental center was selected from each subregion. The study design and protocols were approved by the ethics committee of Najran University (1/40/443), which was conducted according to the guidelines of the Declaration of Helsinki.

\section{Data Collection}

The questionnaire was prepared in Arabic using Google forms (doc.google.com/forms) and was sent to approximately 560 participants via e-mail or WhatsApp. The questionnaire comprised four sections containing both open- and closedended questions. The first section collected basic information of the patient including gender, age, residence, duration of treatment, type of appliance, and type of clinical setup. Section two evaluated the patient's response regarding their interaction with the orthodontist during the duration of the lockdown. Section three assessed the attitude and perception of the patient in regard to their ongoing orthodontic treatment. Section four evaluated patients' mental health status using the Kessler Psychological Distress Scale. ${ }^{8}$ In a previous study, the Arabic version of this scale showed highly acceptable validity and reliability, with Cronbach $\alpha$ ranging from $0.81-0.88 .{ }^{9}$ In this scale, 10 questions were used to assess patients' mental health in the past 4 weeks, with scores between 1 (none of the time) to 5 (all of the time). The total range of the score was from 10-50. A score of 10-19 was considered normal, and respondents were considered likely to be well. A score of 20-24 was considered mild and indicated some level of psychological distress, 25-29 was considered moderate, and 30-50 indicated severe psychological distress.

The questionnaire was validated by an experienced orthodontist to ensure the questions reflected the purpose of the study effectively. Assistance was taken from a questionnaire construction expert to remove or modify confusing and misleading questions. A pilot study was performed to enhance the quality of the questionnaire. Approximately 20 orthodontic patients were sent the questionnaire and asked to specify unclear or confusing questions. A free-response section was left at the end of each question for the respondent to express more information or alternate answers if they needed. The inputs from the pilot study were included and the final questionnaire was prepared to be sent to the study population. On the first page of the form, the purpose of the study was listed along with the time requirement of 8-10 minutes to complete the questionnaire. Respondents were informed that the data was confidential and anonymous. No sign-in or login was required to protect participants' data. Before answering the questions, written informed consent was obtained and parental consent was required for participants under the age of 18 . 


\section{Data Management and Analysis}

The responses for each patient were collected on the Google forms questionnaire, automatically transferred to Google sheets, and downloaded to Excel (version 2019, Microsoft, Redmond, USA). A descriptive analysis was performed to compute the frequency and percentages of patients' responses to the questionnaire. Values were rounded off for better understanding and compilation. A Chi-square test was used to compare the distribution of responses between various parameters of the study. Questions which directly affect patients' mental health were separated, and a logistic regression analysis was performed to assess the association between different responses from the patient. An odds ratio (OR) with 95\% confidence interval (CI) was used as a measure of strength. All the statistical analyses were performed using SPSS for Windows (version 20.0, SPSS IBM, Armonk, New York, USA). A p-value of $<0.05$ was considered to be statistically significant.

\section{Results}

A total of 560 questionnaires were sent to the orthodontic patients. Approximately 512 patients (91\%) answered the forms completely and were included in the study. The descriptive statistics of patients' responses from the first section are shown in Table 1. Approximately 232 males (45\%) and 280 females (55\%) participated in the study, with $62.5 \%$ residing in urban areas and $37.5 \%$ residing in rural areas. Approximately $54 \%$ of the respondents were aged $12-18$ years, $25 \%$ were $18-25$ years, and $21 \%$ were $>25$ years. For $56 \%$ of the participants, the duration since the first treatment was 6 months to 1 year. For approximately 19\%, the treatment had started just 6 months ago, and for $25 \%$, the treatment began more than one year ago. Approximately $92 \%$ had fixed appliances, $6 \%$ had removable appliances, and $2 \%$ were undergoing treatment with aligners.

For the patient's response regarding their interaction with their orthodontist during the lockdown, $63 \%$ of patients did not visit their orthodontist in the past 3-6 months, as shown in Table 2. Approximately $80 \%$ of the patients did not attend their scheduled visits due to being constrained by the mandatory lockdown along with the fear of COVID-19. Communication was established once or twice by $84 \%$ of the patients with their respective orthodontist. About $71 \%$ received a call or message from their orthodontist to inquire about their condition, while $22 \%$ did not receive any kind of communication from their orthodontist.

Table I General Data of the Orthodontic Patients Who Participated in the Study

\begin{tabular}{|c|c|c|c|}
\hline Question (n= 512$)$ & Response & Frequency $(n)$ & Percentage (\%) \\
\hline \multirow[t]{2}{*}{ Gender } & Male & 232 & $45 \%$ \\
\hline & Female & 280 & $55 \%$ \\
\hline \multirow[t]{3}{*}{ Age } & $12-18$ years & 275 & $54 \%$ \\
\hline & $18-25$ years & 130 & $25 \%$ \\
\hline & $>25$ years & 107 & $21 \%$ \\
\hline \multirow[t]{2}{*}{ Residence } & Urban & 320 & $62.5 \%$ \\
\hline & Rural & 192 & $37.5 \%$ \\
\hline \multirow[t]{3}{*}{ Duration since the start of treatment } & $<6$ months & 98 & $19 \%$ \\
\hline & 6 months -1 year & 287 & $56 \%$ \\
\hline & $>$ I year & 127 & $25 \%$ \\
\hline \multirow[t]{3}{*}{ Type of appliance } & Fixed & 470 & $92 \%$ \\
\hline & Removable & 31 & $6 \%$ \\
\hline & Aligners & 13 & $2 \%$ \\
\hline
\end{tabular}


Table 2 Patients' Responses Regarding Their Interaction with the Orthodontist

\begin{tabular}{|c|c|c|c|c|c|}
\hline Questions & Response & Frequency (n) & Percentage (\%) & $\chi^{2}$-value & p-value \\
\hline \multirow[t]{4}{*}{ When was your last visit to your orthodontist? } & $<1$ month & 45 & $9 \%$ & \multirow[t]{4}{*}{282.152} & \multirow[t]{4}{*}{$<0.001$} \\
\hline & I-3 months & 103 & $20 \%$ & & \\
\hline & $3-6$ months & 323 & $63 \%$ & & \\
\hline & $>6$ months & 41 & $8 \%$ & & \\
\hline \multirow[t]{3}{*}{ Why did you stop visiting your orthodontist? } & Mandatory lockdown & 51 & $10 \%$ & \multirow[t]{3}{*}{314.568} & \multirow[t]{3}{*}{$<0.001$} \\
\hline & Afraid of COVID-19 & 50 & $10 \%$ & & \\
\hline & Both & 411 & $80 \%$ & & \\
\hline \multirow[t]{3}{*}{ How many times did you contact your orthodontist? } & Did not contact & 72 & $14 \%$ & \multirow[t]{3}{*}{256.254} & \multirow[t]{3}{*}{$<0.001$} \\
\hline & Once or twice & 431 & $84 \%$ & & \\
\hline & Three or more times & 9 & $2 \%$ & & \\
\hline \multirow[t]{4}{*}{ How many times did your orthodontist check on you? } & Called once & 364 & $71 \%$ & \multirow[t]{4}{*}{195.325} & \multirow[t]{4}{*}{$<0.001$} \\
\hline & Called regularly & 25 & $5 \%$ & & \\
\hline & Called but did not receive & 10 & $2 \%$ & & \\
\hline & Did not call & 113 & $22 \%$ & & \\
\hline
\end{tabular}


Table 3 shows the descriptive statistics of the responses received from the third section of the questionnaire, which evaluated their attitude and perception towards the treatment. About $55 \%$ of the patients were worried. More specifically, $18 \%$ were very worried about not being able to continue their treatment, $72 \%$ percent were worried that their treatment time would increase, and $95 \%$ stated that they would not have started the treatment if they knew the pandemic was coming. About $63 \%$ of the patients followed the instructions from their orthodontist regularly. About $32 \%$ reported poking wires, and $18 \%$ experienced cuts, lacerations, or pain with their braces during lockdown. Seventy-five percent of the patients wished to visit their orthodontist once the lockdown ended, but $6 \%$ were scared to go, while $76 \%$ were not scared to visit as long as the clinic followed the proper preventive measures.

On evaluating the mental health well-being amongst orthodontic patients during lockdown, it was found that the mean and standard deviation of the Arabic version of the Kessler Psychological Distress Scale was $22.76 \pm$ 8.69. Approximately $58 \%$ of the participants reported some kind of psychological distress, scoring $>10$ on the scale. On applying the multiple logistic regression models as shown in Table 4, it was found that female patients $(\mathrm{OR}=1.86,95 \%$ $\mathrm{CI}=1.12-3.21)$ of $>25$ years of age $(\mathrm{OR}=1.94,95 \% \mathrm{CI}=0.90-3.46)$ with duration of treatment $>1$ year $(\mathrm{OR}=5.78$, $95 \% \mathrm{CI}=3.88-9.71)$ had higher odds of mental distress. The patients who did not receive a single call $(\mathrm{OR}=1.62,95 \%$ $\mathrm{CI}=1.12-1.98)$ from their orthodontist during the lockdown and those who were very worried to get their treatment as soon as possible $(\mathrm{OR}=1.61,95 \% \mathrm{CI}=1.05-4.62)$ were associated with higher mental distress. In comparison with the length of treatment time, patients were more worried about the cost of treatment increasing during the pandemic $(\mathrm{OR}=$ $1.58,95 \% \mathrm{CI}=1.09-3.54)$. No significant differences in patients' mental health status were observed among those having different treatment modalities.

\section{Discussion}

It is said that the toughest times bring out the true nature of one's resilience. The current pandemic is one such situation for orthodontic patients, the orthodontist, and the orthodontic team. Since the oral cavity is a major route for the entry and exit of the virus, it leaves dental professionals and their clinics more vulnerable to the spread and cross infection of COVID-19. ${ }^{10}$ Although many guidelines and protocols for standard infection control have been proposed and implemented worldwide, even these measures are not effective to limit the spread of the coronavirus. ${ }^{11}$ It can be argued that lockdowns and curfews were the only viable options available to the government and health authorities to control the rapid spread of the virus. Consequently, dental clinics were shut down, and orthodontic care was severely affected across the Kingdom. To understand the ramifications of this lockdown on Saudi orthodontic patients, this study was conducted to assess their perception and mental health status via an online questionnaire-based study.

The study sample was a good representation of orthodontic patients undergoing treatment across Saudi Arabia. Most of the respondents (84\%) contacted their orthodontist during the pandemic and comparatively less contact (71\%) was made by the orthodontist to their patients. Unfortunately, $22 \%$ of orthodontists did not call or message their patients during lockdown. Such patients were found to be more anxious and in distress regarding their treatment. This is concerning, as inquiring about the progress of their treatment and assessing the overall condition of the patient is the primary responsibility of the orthodontist and their team. Reassuring the patient about what could happen and what will not happen can be a potential tool to motivate the patient and alleviate their fears regarding the treatment. ${ }^{12}$ The concept of tele-orthodontics can be employed specifically during this period to digitally monitor the patients without having to visit the clinic in person. ${ }^{13,14}$ A short call or message from the orthodontist or their office could help boost the confidence of the patient and provide some comfort. Recent studies have found that tele-monitoring and remote monitoring are positive approaches to evaluate the orthodontic health status of the patient in this pandemic era. ${ }^{15,16}$ The use of smartphones and digital technology can be useful in evaluating the progression of the treatment and improving the patient's cooperation. ${ }^{17}$

Due to the current pandemic, $63 \%$ of the patients could not visit their orthodontist for the last 3-6 months. Despite this long period, a good number (63\%) of patients regularly followed the instructions given by their orthodontist. Patient compliance can be a major problem in orthodontics because a failure to maintain good oral hygiene can lead to other deleterious effects on enamel and periodontium. ${ }^{18}$ Long periods without checkups can lead to many problems that were otherwise solved easily in the pre-pandemic era. Poking of the distal ends of the archwire, cuts and lacerations from the 
Table 3 Patients' Responses Regarding Their Attitude and Perception of Orthodontic Treatment

\begin{tabular}{|c|c|c|c|c|c|}
\hline Question (n = 512) & Response & Frequency (n) & Percentage (\%) & $\chi^{2}$-value & p-value \\
\hline \multirow[t]{4}{*}{$\begin{array}{l}\text { Are you worried about not being able to regularly } \\
\text { continue your orthodontic treatment? }\end{array}$} & $\begin{array}{l}\text { Not concerned about the } \\
\text { pandemic }\end{array}$ & 35 & $7 \%$ & \multirow[t]{4}{*}{106.752} & \multirow[t]{4}{*}{$<0.001$} \\
\hline & $\begin{array}{l}\text { Not so worried, treatment } \\
\text { can wait }\end{array}$ & 103 & $20 \%$ & & \\
\hline & Worried & 282 & $55 \%$ & & \\
\hline & $\begin{array}{l}\text { Very worried to get my } \\
\text { treatment done as soon as } \\
\text { possible }\end{array}$ & 92 & $18 \%$ & & \\
\hline \multirow{4}{*}{$\begin{array}{l}\text { What are you most worried about concerning your } \\
\text { orthodontic treatment? }\end{array}$} & Treatment time will increase & 369 & $72 \%$ & \multirow[t]{4}{*}{268.675} & \multirow[t]{4}{*}{$<0.001$} \\
\hline & Treatment may go wrong & 48 & $9 \%$ & & \\
\hline & Treatment cost will increase & 70 & $14 \%$ & & \\
\hline & Relapse will occur & 25 & $5 \%$ & & \\
\hline \multirow{2}{*}{$\begin{array}{l}\text { Would you have started the treatment if you knew } \\
\text { about the pandemic? }\end{array}$} & Yes & 26 & $5 \%$ & \multirow[t]{2}{*}{345.235} & \multirow[t]{2}{*}{$<0.001$} \\
\hline & No & 486 & $95 \%$ & & \\
\hline \multirow{3}{*}{$\begin{array}{l}\text { Are you following instructions like maintaining good } \\
\text { oral hygiene, elastics wear, and avoiding hard and sticky } \\
\text { food? }\end{array}$} & Yes & 323 & $63 \%$ & \multirow[t]{3}{*}{185.579} & \multirow[t]{3}{*}{$<0.001$} \\
\hline & No & 47 & $9 \%$ & & \\
\hline & Sometimes & 142 & $28 \%$ & & \\
\hline \multirow{6}{*}{$\begin{array}{l}\text { What are the problems you faced with your appliance } \\
\text { during the lockdown? }\end{array}$} & Loose brackets and bands & 99 & $19 \%$ & \multirow[t]{6}{*}{55.354} & \multirow[t]{6}{*}{$<0.001$} \\
\hline & Poking wires & 163 & $32 \%$ & & \\
\hline & Elastic over & 70 & $14 \%$ & & \\
\hline & Gum swelling & 89 & $17 \%$ & & \\
\hline & Pain & 67 & $13 \%$ & & \\
\hline & Re-opening of spaces & 24 & $5 \%$ & & \\
\hline \multirow{3}{*}{$\begin{array}{l}\text { Did you experience any emergency problems like cuts, } \\
\text { lacerations, or pain with braces? }\end{array}$} & No & 420 & $82 \%$ & \multirow[t]{3}{*}{274.658} & \multirow[t]{3}{*}{$<0.001$} \\
\hline & Yes, called my orthodontist & 51 & $10 \%$ & & \\
\hline & $\begin{array}{l}\text { Yes, did self-treatment using } \\
\text { the internet }\end{array}$ & 41 & $8 \%$ & & \\
\hline \multirow{3}{*}{$\begin{array}{l}\text { When do you plan to visit your orthodontist once the } \\
\text { lockdown ends? }\end{array}$} & As soon as possible & 384 & $75 \%$ & \multirow[t]{3}{*}{165.349} & \multirow[t]{3}{*}{$<0.001$} \\
\hline & $\begin{array}{l}\text { Will wait for the } \\
\text { orthodontist to schedule me }\end{array}$ & 92 & $18 \%$ & & \\
\hline & $\begin{array}{l}\text { Will not go until the } \\
\text { pandemic is over }\end{array}$ & 36 & $7 \%$ & & \\
\hline \multirow{3}{*}{$\begin{array}{l}\text { Are you scared to visit a dental health facility or clinic } \\
\text { once the lockdown ends? }\end{array}$} & Yes, I am scared & 30 & $6 \%$ & \multirow[t]{3}{*}{248.371} & \multirow[t]{3}{*}{$<0.001$} \\
\hline & No, I will go anyways & 92 & $18 \%$ & & \\
\hline & $\begin{array}{l}\text { No, but I will go if } \\
\text { preventive health measures } \\
\text { are taken }\end{array}$ & 389 & $76 \%$ & & \\
\hline
\end{tabular}


Table 4 Regression Analysis for Patients' Responses Related to Basic Information, Perception, and Attitude Using the Kessler Psychological Distress Scale (KI0)

\begin{tabular}{|c|c|c|c|c|c|}
\hline Variables & Response & $\begin{array}{l}\text { Odds } \\
\text { Ratio }\end{array}$ & KIO Score & $95 \% \mathrm{Cl}$ & p-value \\
\hline \multirow[t]{2}{*}{ Gender } & Male & Reference & $|8.5| \pm 6.25$ & Reference & $0.008^{*}$ \\
\hline & Female & 1.86 & $24.69 \pm 7.28$ & $1.12-3.21$ & \\
\hline \multirow[t]{3}{*}{ Age } & $12-18$ years & Reference & $15.74 \pm 5.98$ & Reference & $0.042^{*}$ \\
\hline & 18-25 years & 1.54 & $20.06 \pm 6.74$ & $1.04-2.85$ & $0.017^{*}$ \\
\hline & $>25$ years & 1.94 & $24.86 \pm 7.52$ & $0.90-3.46$ & $0.007^{*}$ \\
\hline \multirow[t]{3}{*}{ Duration since the beginning of treatment } & $<6$ months & Reference & $16.25 \pm 4.55$ & Reference & $0.00 I^{*}$ \\
\hline & 6 months-I year & 3.42 & $18.52 \pm 5.98$ & $2.61-6.09$ & $0.032 *$ \\
\hline & $>$ I year & 5.78 & $23.14 \pm 6.35$ & $3.88-9.7 \mid$ & $0.002 *$ \\
\hline \multirow{4}{*}{$\begin{array}{l}\text { How many times did your orthodontist check on } \\
\text { you? }\end{array}$} & Called once & Reference & $17.22 \pm 5.72$ & Reference & $0.033^{*}$ \\
\hline & Called regularly & 0.42 & $17.09 \pm 6.46$ & $0.21-0.69$ & $0.049 *$ \\
\hline & Called but did not receive & 0.56 & $\mid 7.66 \pm 6.01$ & $0.39-0.78$ & 0.217 \\
\hline & Did not call & 1.62 & $20.56 \pm 7.11$ & $1.12-1.98$ & 0.368 \\
\hline \multirow[t]{4}{*}{$\begin{array}{l}\text { Are you worried about not being able to regularly } \\
\text { continue your orthodontic treatment? }\end{array}$} & $\begin{array}{l}\text { No, not concerned about the } \\
\text { pandemic }\end{array}$ & Reference & $18.22 \pm 6.33$ & Reference & $0.001 *$ \\
\hline & $\begin{array}{l}\text { Not so worried, treatment can } \\
\text { wait }\end{array}$ & 0.77 & $|7.22 \pm 7.0|$ & $0.21-0.88$ & $0.011^{*}$ \\
\hline & Worried & 1.25 & $21.84 \pm 6.16$ & $1.01-2.43$ & $0.029 *$ \\
\hline & $\begin{array}{l}\text { Very worried to get my } \\
\text { treatment done as soon as } \\
\text { possible }\end{array}$ & 1.61 & $22.94 \pm 6.34$ & $1.05-4.62$ & $0.042^{*}$ \\
\hline \multirow{4}{*}{$\begin{array}{l}\text { What are you most worried about concerning } \\
\text { your orthodontic treatment? }\end{array}$} & Treatment time will increase & Reference & $18.22 \pm 7.55$ & Reference & 0.128 \\
\hline & Treatment may go wrong & 0.32 & $|7.9| \pm 6.38$ & $0.12-0.65$ & 0.155 \\
\hline & Treatment cost will increase & 1.58 & $20.5 I \pm 5.4 I$ & $1.09-3.54$ & 0.119 \\
\hline & Relapse will occur & 0.59 & $19.56 \pm 7.55$ & $0.45-0.95$ & 0.186 \\
\hline
\end{tabular}

Note: *Indicates the logistic regression test is significant at $<0.05$.

braces were the among the most common problems faced by patients. Gum swelling, pain, and reopening of spaces were some other issues reported by patients. Similar findings have been reported by studies conducted on the Brazilian, ${ }^{19}$ Indian, ${ }^{20}$ and Syrian ${ }^{21}$ population. For the majority of patients, overextended wire from the buccal tubes resulted in trauma to the mucosa and tongue. Additionally, debonding of the brackets and buccal tubes, fracture of bands, fraying of ligature ties, and breakage of elastomeric chains were some of the other complications faced by the patients during the pandemic. Using a nail clipper to cut the distal ends of the wire, applying relief wax to secure a loose bracket or band, using various mouthwashes for bleeding gums, applying gels to ulcers, and taking painkillers were some of the measures reported by patients to remedy these problems. ${ }^{12,22}$ Virtual support through audio-visual interactions is an inexpensive and valuable method for providing information related to such emergency situations. ${ }^{23}$

In this study, $95 \%$ of the patients reported that they would not have started the treatment if they knew the pandemic was coming. This negative response is significant and reflects the fear of COVID-19 amongst patients. Approximately 
$72 \%$ of the patients were more worried about the lengthening duration of treatment than the cost of treatment increasing once the clinic opened. This might be justified on a case-by-case basis, but the orthodontic community should be compassionate towards this situation. Dental professionals have a moral duty to reduce the fear amongst their patients and their families but are concerned about the financial consequences of it. Additional costs arising from the use of standard infection control, sanitization measures, and personal protection equipment kits can be passed on to the patients. In this study, it was found that more than half (55\%) of the patients were worried and $18 \%$ were very worried, as they were unable to continue their treatment. On the positive side, approximately $76 \%$ of the patients wished to visit their orthodontist once the lockdown ended, only if proper preventive measures were employed in the clinic. This finding is in accordance with previous studies where the majority of the patients were worried about not attending the clinic and their treatment time lengthening as a result. ${ }^{7,24}$ Orthodontic treatment is one of the lengthiest types of dental treatments, and each missed appointment can extend the treatment time by 1.09 months. ${ }^{25}$ However, orthodontic procedures carry a low risk of infection, as aerosols are not generated. This can be considered as a strategic advantage, and patients can be reassured to resume their orthodontic treatment. Hence, the orthodontist should take certain precautionary steps, such as allowing only the patient into the operatory area, ensuring proper disinfection after each patient, reducing the number of patients in the waiting area, and undertaking a limited number of appointments per day. In addition, reassuring the patients about the safety of their clinic can increase patient satisfaction, confidence, and cooperation with the treatment.

In this study, the majority of participants (58\%) reported some level of mental distress owing to their treatment and the lockdown. A mild level of anxiety and psychological distress was found in the complete sample. Female patients were found to be more anxious than males, particularly females $>25$ years of age with more than one year into their orthodontic treatment. This finding is in accordance with results of other recent studies which have reported a higher level of anxiety and mental distress in female patients as compared with males. ${ }^{7,24,26,27}$ This can be attributed to the fact that females are more emotionally affected by difficult situations and hence report higher levels of stress and anxiety. ${ }^{28}$ Moreover, their concern for finishing their treatment early, transportation problems during the pandemic, and other problems related to family, health, and finances can increase the burden on their mental well-being. Thus, it can be inferred that long durations of extended lockdown periods can accentuate the mental health problems for a number of patients. Additional measures to enhance the orthodontist-patient relationship are strongly recommended to relieve patients' levels of stress and anxiety.

While this study had some significant findings, it also had some limitations. It was an online survey, so there was a possibility of reporting bias. The sample was non-probabilistic with no population generalization. Nevertheless, it provided a quick and fair overview of the problems and perceptions of Saudi orthodontic patients during the lockdown. All the orthodontic patients, regardless of the time they initiated treatment, were included in the study. This could lead to possible heterogeneity of the sample. Further case control and prospective cohort studies are recommended to study multitude of problems faced by the orthodontist and their patients in this COVID-19 pandemic.

\section{Conclusion}

In this study, it was found that almost every orthodontic patient was affected by the ongoing pandemic for some problem regarding the continuation of their treatment. Many patients reported poking wires, pain, or laceration as their main concern during the lockdown. Most of the patients were willing to visit their orthodontist once the lockdown ended, provided the clinic adhered to proper preventive measures. However, the approach of the orthodontist in taking mental and emotional care of their patients during the pandemic was overall inadequate.

A mild level of mental distress was experienced by the Saudi orthodontic population, and over half of the patients faced some level of psychological anxiety during the pandemic. This study also concluded that females $>25$ years of age with more than one year of ongoing treatment, those who were not contacted by their orthodontist even once, and those who wished to complete their treatment as soon as possible all experienced higher levels of mental distress. Therefore, the authors suggest that establishing contact with patients (particularly females and those with long treatment durations), inquiring about their treatment condition, and providing some kind of reassurance on a regular basis might help in allaying their stress and anxiety levels in these difficult times. 


\section{Acknowledgments}

The authors would like to thank the patients who sincerely participated in the study.

\section{Disclosure}

The authors report no conflicts of interest in this work.

\section{References}

1. Sohrabi C, Alsafi Z, O'Neill N, et al. World Health Organization declares global emergency: a review of the 2019 novel coronavirus (COVID- 19). Int J Surg. 2020;76:71-76. doi:10.1016/j.ijsu.2020.02.034

2. Saudi Arabia announces first case of coronavirus [Internet]. Arab News; 2020. Available from: https://arab.news/6xyan. Accessed March $20,2021$.

3. Saudi Gazette. Saudi Arabia to enforce 24-hour curfew from May 23 to 27 - Saudi Gazette [Internet]; 2020. Available from: https://saudigazette. com.sa/article/593034. Accessed April 12, 2021.

4. Peng X, Xu X, Li Y, Cheng L, Zhou X, Ren B. Transmission routes of 2019-nCoV and controls in dental practice. Int J Oral Sci. $2020 ; 12: 9$. doi:10.1038/s41368-020-0075-9

5. World Health Organization. Considerations for the provision of essential oral health services in the context of COVID-19. Interim Guid. 2020;2020:1-5.

6. American Dental Association - ADA. Coronavirus frequently asked questions; 2020 [cited March 16, 2020]. Available from: https://success.ada. org/en/practice-management/patients/coronavirus-frequently-asked-questions. Accessed January 28, 2022.

7. Peloso RM, Pini NIP, Sundfeld Neto D, et al. How does the quarantine resulting from COVID-19 impact dental appointments and patient anxiety levels? Braz Oral Res. 2020;34:e84. doi:10.1590/1807-3107bor-2020.vol34.0084

8. Andrews G, Slade T. Interpreting scores on the Kessler Psychological Distress Scale (K10). Aust N Z J Public Health. 2001;25:494-497. doi:10.1111/j.1467-842X.2001.tb00310.x

9. Easton SD, Safadi NS, Wang Y, Hasson RG 3rd. The Kessler psychological distress scale: translation and validation of Arabic version. Health Qual Life Outcomes. 2017;15(1):215. doi:10.1186/s12955-017-0783-9

10. Isiekwe IG, Adeyemi TE, Aikins EA, Umeh OD. Perceived impact of COVID-19 pandemic on orthodontic practice by orthodontist and orthodontic residents in Nigeria. $J$ World Fed Orthod. 2020;9(3):123-128.

11. Meng L, Hua F, Bian Z. Coronavirus disease 2019 (COVID-19): emerging and future challenges for dental and oral medicine. J Dent Res. 2020;99 (5):481-487. doi:10.1177/0022034520914246

12. Suri S, Vandersluis YR, Kochhar AS, Bhasin R, Abdallah M-N. Clinical orthodontic management during the COVID-19 pandemic. Angle Orthod. 2020;90(4):473-484. doi:10.2319/033120-236.1

13. Saccomanno S, Quinzi V, Sarhan S, Laganà D, Marzo G. Perspectives of teleorthodontics in the COVID-19 emergency and as a future tool in daily practice. Eur J Paediatr Dent. 2020;21:157e62.

14. Moylan HB, Carrico CK, Lindauer SJ, Tüfekçi E. Accuracy of a smartphone-based orthodontic treatment-monitoring application: a pilot study. Angle Orthod. 2019;89:727e33. doi:10.2319/100218-710.1

15. Dalessandri D, Sangalli L, Tonni I, et al. Attitude towards telemonitoring in orthodontists and orthodontic patients. Dent J. $2021 ; 9(5): 47$. doi:10.3390/dj9050047

16. Bianco A, Dalessandri D, Oliva B, et al. COVID-19 and orthodontics: an approach for monitoring patients at home. Open Dent J. 2021;15:87-96. doi: $10.2174 / 1874210602115010087$

17. Sangalli L, Savoldi F, Dalessandri D, et al. Effects of remote digital monitoring on oral hygiene of orthodontic patients: a prospective study. $B M C$ Oral Health. 2021;21(1):435. doi:10.1186/s12903-021-01793-9

18. Bartsch A, Witt E, Sahm G, Schneider S. Correlates of objective patient compliance with removable appliance wear. Am J Orthod Dentofacial Orthop. 1993;104(4):378-386. doi:10.1016/S0889-5406(05)81337-X

19. Cotrin P, Peloso RM, Pini NIP, et al. Urgencies and emergencies in orthodontics during coronavirus disease 2019 pandemic: Brazillian orthodontists' experience. Am J Orthod Dentofacial Orthop. 2020;158(5):661-667. doi:10.1016/j.ajodo.2020.06.028

20. Shenoi SB, Deshpande S, Jatti R. Impact of COVID-19 lockdown on patients undergoing orthodontic treatment: a questionnaire study. J Indian Orthod Soc. 2020;54(3):195-202. doi:10.1177/0301574220942233

21. Bustati N, Rajeh N. The impact of COVID-19 pandemic on patients receiving orthodontic treatment: an online questionnaire cross-sectional study. $J$ World Fed Orthod. 2020;9(4):159-163.

22. Caprioglio A, Pizzetti GB, Zecca PA, Fastuca R, Maino G, Nanda R. Management of orthodontic emergencies during 2019-NCOV. Prog Orthod. 2020;21:10. doi:10.1186/s40510-020-00310-y

23. Webster P. Virtual health care in the era of COVID-19. Lancet. 2020;395(10231):1180-1181. doi:10.1016/S0140-6736(20)30818-7

24. Martina S, Amato A, Faccioni P, et al. The perception of COVID-19 among Italian dental patients: an orthodontic point of view. Prog Orthod. 2021;22(1):11. doi:10.1186/s40510-021-00355-7

25. Beckwith FR, Ackerman RJ Jr, Cobb CM, Tira DE. An evaluation of factors affecting duration of orthodontic treatment. Am J Orthod Dentofacial Orthop. 1999;115(4):439-447. doi:10.1016/S0889-5406(99)70265-9

26. Cotrin P, Peloso RM, Oliveira RC, et al. Impact of Corona virus pandemic in appointments and anxiety/concerns of patients regarding orthodontic treatment. Orthod Craniofac Res. 2020;23(4):455-461. doi:10.1111/ocr.12395

27. Xiong X, Wu Y, Fang X, et al. Mental distress in orthodontic patients during the coronavirus disease 2019 pandemic. Am J Orthod Dentofacial Orthop. 2020;158(6):824-833. doi:10.1016/j.ajodo.2020.07.005

28. Moser JS, Moran TP, Kneip C, Schroder HS, Larson MJ. Sex moderates the association between symptoms of anxiety, but not obsessive compulsive disorder, and error-monitoring brain activity: a meta-analytic review. Psychophysiol. 2016;53(1):21-29. doi:10.1111/psyp.12509 


\section{Publish your work in this journal}

Patient Preference and Adherence is an international, peer-reviewed, open access journal that focusing on the growing importance of patient preference and adherence throughout the therapeutic continuum. Patient satisfaction, acceptability, quality of life, compliance, persistence and their role in developing new therapeutic modalities and compounds to optimize clinical outcomes for existing disease states are major areas of interest for the journal. This journal has been accepted for indexing on PubMed Central. The manuscript management system is completely online and includes a very quick and fair peer-review system, which is all easy to use. Visit http://www.dovepress.com/testimonials.php to read real quotes from published authors.

Submit your manuscript here: https://www.dovepress.com/patient-preference-and-adherence-journal 